Int. J. Electrochem. Sci., 14 (2019) 9504 - 9519

International Journal of

ELECTROCHEMICAL

SCIENCE

www.electrochemsci.org

\title{
A Novel Dioxythiophene Based Conducting Polymer as Electrode Material for Supercapacitor Application
}

\author{
Mehmet Giray Ersozoglu1, Hans-Detlev Gilsing ${ }^{2}$, Aslı Gencturk ${ }^{3}$ and A. Sezai Sarac ${ }^{1,3 *}$ \\ ${ }^{1}$ Polymer Science and Technology, Istanbul Technical University, Istanbul 34469, Turkey \\ ${ }^{2}$ Institute of Thin Film and Microsensoric Technology (IDM), Kantstr. 55, 14513 Teltow, Germany \\ ${ }^{3}$ Nanoscience and Nanoengineering, Istanbul Technical University, Istanbul 34469, Turkey \\ *E-mail: sarac@itu.edu.tr
}

doi: $10.20964 / 2019.10 .35$

Received: 5 July 2019 / Accepted: 6 August 2019 / Published: 30 August 2019

\begin{abstract}
The electrochemical polymerization of the functionalized 3,4-propylenedioxythiophene derivative ProDOT-EtO-BZA 1 bearing an oligoether spacer with aromatic carboxylic group was achieved on platinum (Pt) wire and screen printed carbon electrode (SPCE), respectively. The structure, morphology and electrochemical properties of the PProDOT-EtO-BZA films were analyzed by FT-IR, SEM, AFM and electrochemical impedance spectroscopy (EIS), respectively. Furthermore, poly(3,4propylenedioxythiophene) (PProDOT), the 2,2-dibenzyl derivative (PDBProDOT) and the 2,2-diethyl derivative (PProDOT-Et2) were electrodeposited onto SPCE via cyclic voltammetry (CV) for comparison of the capacitance performance of these PProDOTs in organic electrolytes to the corresponding data of PProDOT-EtO-BZA. CV and EIS measurements of the PProDOT-EtO-BZA revealed pseudocapacitive behavior with faradaic reactions. Specific and low frequency capacitance $\left(20.8 \mathrm{mF} / \mathrm{cm}^{2}\right.$ and $8.5 \mathrm{mF} / \mathrm{cm}^{2}$, respectively) of the PProDOT-EtO-BZA were almost two times higher than those of the other PProDOTs. These results suggest that PProDOT-EtO-BZA films can be utilized as electrode material for supercapacitors.
\end{abstract}

Keywords: ProDOT, Supercapacitor, Electrochemical Impedance Spectroscopy, Equivalent-Circuit Model, Screen Printed Electrode.

\section{FULL TEXT}

(C) 2019 The Authors. Published by ESG (www.electrochemsci.org). This article is an open access article distributed under the terms and conditions of the Creative Commons Attribution license (http://creativecommons.org/licenses/by/4.0/). 